\title{
EDITORIAL
}

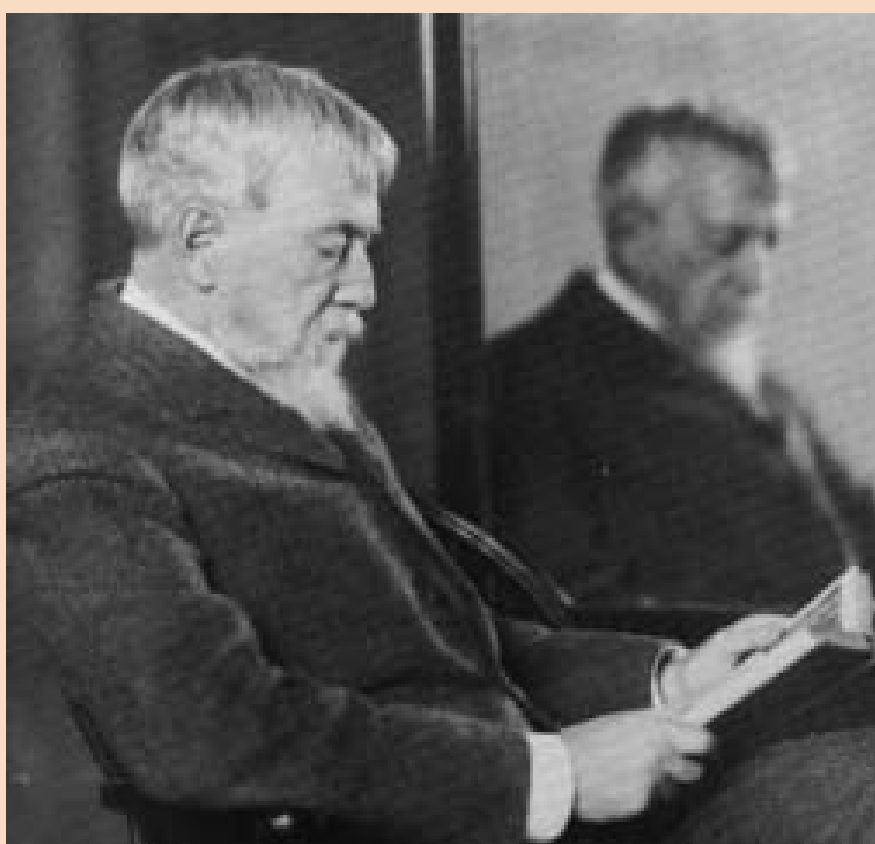

Although of Scottish origin, Silas Weir Mitchell (1829-1914) was born in Philadelphia. His writings on nerve and related injuries from his experiences in the American Civil War became classics, as did his description of causalgia. He also reported on postparalytic chorea, erythromelalgia (Weir Mitchell's disease) and cerebellar function. He is considered the most eminent American neurologist of his time. It is less often appreciated that he was a master of psychological and behavioural managment, especially with his neurasthenia cases.

A vid journal readers will have come across an explosion of editorials about the need to build bridges between the specialities of neurology and psychiatry (Ross 2003; Baker et al. 2002; Cowan \& Kandel 2001; M artin 2002). Indeed, the fact they became separated at all might be regarded as a historical accident, driven by early scientific understanding of the simpler parts of thenervoussystem on theonehand and theneed to contain thedisturbed behaviour of thosewith psychosison the other, all underpinned by mind body dualism. What advantages could there bein breaking down the barriers?

The authors of these editorials have focused on opportunities for increased scientific understanding of theneurobiological basis of subjectivepsychiatric phenomena. And as a topic for research, linked to the promise of neuroscience in general and functional brain imaging in particular, this is indeed a desirable endeavour. But what are the advantages of greater communication between neurology and psychiatry for day-to-day clinical practice?

Clearly, neurologists could teach many things to psychiatrists. Careful attention to the details of a history, a systematic physical

\section{What do} neurologists need to know about

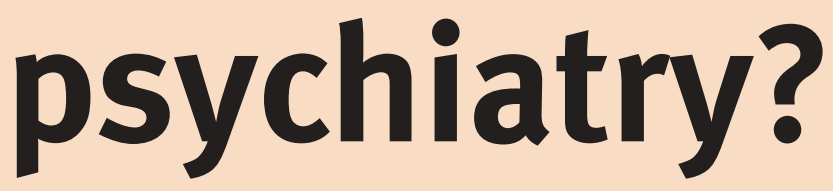

examination and in a moregeneral sense how to maintain a high level of credibility and prestige for ones speciality. But can the practical neurologist learn anything from clinical psychiatry? Whilst weunderstand that somemay doubt this, wewould liketo suggest that they might.

The difficulty for clinical psychiatry is that, almost by definition, it is medicine without signs or tests. So the challenge for psychiatrists has been to elicit, assess and create diagnoses from their patients' subjectivepersonal experiencesand then to develop effective therapeutic interventions. And, by and large, psychiatry has done remarkably well in addressing this problem. There is a body of work that provides a detailed description of 'psychopathology', that istherange of symptomsand abnormal experiences commonly reported. There is an established classification of this psychopathology into diagnostic categories which, although ultimately without biological validity, are as reliable as many other diagnoses in medicine (migraine for example), and they predict response to treatment. There is also a system for formulating aetiology in a biopsychosocial framework that allows considera- 
tion of multiple aetiological factors. And finally, there are treatments that work, many of which are substantially more effective than some of the treatments currently availableto neurologists.

\section{HOW COULD ALL THIS HELP THE NEUROLOGIST?}

We have found that fully a third of new neurology outpatients have subjective symptoms that are regarded by consultant neurologists as inadequately explained by objectively definableneurological disease, and that neurologists find these patients more difficult to help (Carson et al. 2000a). M oreover, thesepatientsare as disabled as those with neurological disease, more distressed, and they do not automatically improvefollowing a neurological consultation. Clearlycurrent day-to-day clinical practicerequires the modern neurologist to attend not only to the patients' neurological lesion, but also to wider aspects of their presentation, and in particular their symptoms. It is our contention therefore that themain things that clinical neurologists need to learn from psychiatry are how to elicit, assess and manage symptoms that are not clearly related to structural neurological disease. M ost of thesepatientshavesomatic and psychological symptoms consistent with psychiatric diagnoses of depression, anxiety and panic disorder, which can betreated effectively. Othershave functional symptoms and syndromes such as the chronic fatigue syndrome or conversion disorder whoseaetiology iscurrently unknown but in which the efficacy of antidepressant drugs and behavioural treatments has been convincingly demonstrated. All can be usefully considered as having potentially reversible disturbances of nervous system functioning

So the top five things we think neurologists might learn from psychiatry are:

1 To ask patients who present with somatic symptoms about other psychological symptoms and so to diagnose psychiatric disorderssuch as depression, anxiety and panic disorder. This skill is perhaps best acquired by training in a formal structured psychiatric interview (First et al. 1999). It is al so necessary to learn how to ask these question s of a patient in a way that seems consistent with a general medical assessment and that is not overtly 'psychiatric'. One place to learn these skillsisin a liaison psychiatry clinic.

2 To provide effective reassurance. This requires finding out about the patients' concerns and beliefs, beforetelling them what they don't have - a structural disorder of the nervous system - so that the reassurance is appropriately targeted (Warwick \& Salkovskis 1985). And then giving them some idea of what they do have, which is often a disturbance of nervous system functioning.

3 In patients with chronic neurological conditions, such as Parkinson's disease, to be aware that the coexistence of a psychiatric condition (psychiatric comorbidity), such as depression, greatly exacerbatessymptom burden and disability (Carson et al. 2000b) and therefore merits clinical attention

4 To know enough about antidepressant agents to be able to choose between a few of them and prescribethem in thecorrect doseand for theright duration. Themost common error is too little for too short a time. And to beable to explain to patientstherationalefor antidepressant medication in a way that is acceptable to them. This is often achieved by explaining that the drugs work on the brain to reduce a variety of symptoms of nervous dysfunction such as pain and sleep disturbance, rather than pressing the diagnosis of depression onto a reluctant patient (Sharpe\& Carson 2001).

5 To beableto identify the need for, and to explain to patients, the role of psychological therapies. This is usually better achieved by emphasizing that such treatment helps develop effectivecoping strategies, rather than depictingtheprocessas an exploration of the psychogenic origin of their symptoms. $\mathrm{Historically} \mathrm{there} \mathrm{was} \mathrm{no} \mathrm{clear} \mathrm{boundary} \mathrm{between} \mathrm{clinical} \mathrm{neu-}$ rology and clinical psychiatry. Some of the great early figures of neurology such as Silas Weir M itchell, of necessity used largely behavioural and psychological interventions in themanagement of patients ( $M$ itchell 1884). Of course, they had fewer tests to do and more time to spend with the patient. Nonetheless, it is our view that an increasing dialogue between neurology and psychiatry would not only improve psychiatrists' ability to understand specific malfunctions of the nervous system, but could also improve neurologists' ability to manage patients who suffer from subjective symptoms related to those higher levels of brain functioning long studied by psychiatrists. This should improve patient outcomes and makemanaging these patients much more satisfying and enjoyable for the neurologist.

\section{EDITORIAL COMMENT}

In the next issue of Practical Neurology we are publishing an article by Allan House on defining, recognizing and managing depression in neurological practice.

CharlesWarlow

\section{REFERENCES}

Baker M G, Kale R \& M enken M (2002) The wall between neurology and psychiatry. British M edical Journal, 324, 1468-9.

Carson AJ, Ringbauer B, MacKenzie L.et al. (2000b) Neurological disease, emotional disorder, and disability: they are related: a study of 300 consecutive new referrals to a neurology outpatient department. Journal of Neurology, Neurosurgery and Psychiatry, 68, 202-6.

Carson AJ, Ringbauer B, Stone J.et al. (2000a) Do medically unexplained symptoms matter? A prospective cohort study of 300 new referrals to neurology outpatient clinics. Journal of Neurology, Neurosurgery and Psychiatry, 68, 207-10.

Cowan WM \& Kandel ER (2001) Prospects for neurology and psychiatry. Journal of theAmerican M edical Association, 285, 594-600.

First M B, Spitzer RL, Gibbon M . et al. (1999) Structured Clinical Interview for DSM -IV AxisI Disorders. Biometrics Research, New York StatePsychiatric Institute, USA.

$M$ artin JB (2002) Theintegration of neurology, psychiatry, and neuroscience in the21st century. American Journal of Psychiatry, 159, 695-704.

M itchell SW (1884) Fatand Blood: an Essay on theTreatment of Certain Forms of N eurasthania and $\mathrm{H}$ ysteria. J.B.Lippincott, London.

Ross DE (2003) Psychiatry and Neurology. American Journal of Psychiatry, 160, 596.

SharpeM \& Carson AJ (2001) 'Unexplained' Somatic Symptoms, Functional Syndromes, and Somatization: Do We Need a Paradigm Shift? Annals of Internal M edicine, 134, 926-30.

Warwick HM \& Salkovskis PM (1985) Reassurance. British M edical Journal, 290, 1028 